\title{
The Contingency of Possibility
}

\author{
JEAN-YVES BÉZIAU
}

\begin{abstract}
In this paper we criticize the way possibility is characterized in contemporary modal logic through the diamond operator. We explain that it does not match with the usual notion of possibility and that this notion is better described by the vertex $\mathrm{Y}$ of the hexagon of opposition usually called contingency.
\end{abstract}

Keywords: Possibility; contingency; Necessity, aquare of opposition; hexagon of opposition; modal logic.

Dedicated to Fabien Schang for his 40th birthday

S'il est possible qu'il ne pleuve pas, il est donc possible qu'il pleuve, par consequent je dois nécessairement sortir avec mon parapluie au risque de mouiller mon intelligence

Baron de Chambourcy

\section{Possibility of Rain in Acapulco}

Yanet is presenting the weather forecast in Acapulco. Sometimes she says "It might rain tomorrow in Acapulco". This does not exclude that it will not rain. This contrasts with "It surely will rain tomorrow in Acapulco", which is almost synonymous to "It will rain tomorrow in Acapulco". We have here two opposite moods. On each side we may have some light variations, keeping the spirit of this contrary opposition. To an idea is associated a cloud of expressions. In the present case, let us distinguish a white cloud from a black cloud:

\begin{tabular}{|l|l|}
\hline \multicolumn{1}{|c|}{ White Cloud } & \multicolumn{1}{c|}{ Black Cloud } \\
\hline It might rain & It certainly will rain \\
\hline It could rain & It must rain \\
\hline It possibly will rain & It surely will rain \\
\hline
\end{tabular}

Below the labelling line, on the three remaining lines of the table, we have two expressions on each line. This does not mean that on a given line the expression on the left column is specifically the contrary of the expression which on the right column. Given an expression of the white cloud, any expression of the black cloud is contrary to it and vice versa. We are using "contrary" here in the technical sense of 
the theory of the square of opposition: two propositions are contrary iff they cannot be true together but can be false together. Contrary is not the same as contradictory, case where the two propositions can moreover not be false together.

Contrary is in natural language most of the time used as synonymous to contradictory and there is not a specific word to refer to the notion of contrariety by opposition to the notion of contradiction. Nevertheless everybody can easily understand this notion and the difference between the two. "It could rain" is contrary to "It is surely will rain" because the two propositions cannot be true together but can be false together, in the case it is impossible that it will rain. ${ }^{1}$

\section{Diamond, a Symbol for Possibility}

In contemporary modal logic we have two main characters, two unary operators, represented by the signs " " and " ", literally read as "diamond" and "box", or less profanely as "possible" and "necessary".

Let us emphasize that the words "diamond" and "possible" can be considered as names for the sign " ", but that the sign " " itself is a name for an operator having some properties relative to the logical machinery in which it is embodied. So we can talk without quotation marks about in the same way that we can talk without quotation marks about possibility. Generally we are not talking about signs, but about their meanings. The name given to a sign may reflect what the sign is by itself or/and its meaning. "Diamond" reflects rather the sign " " and "possible" rather the meaning of " ", unless we consider possibility as a gem.

Let us have a look at the following traffic sign:

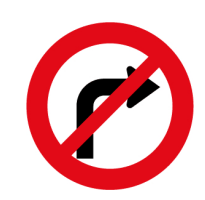

It is called "No right turn", a beautiful name that reflects its meaning not the sign itself. However there is here a strong connection between the sign and its meaning. This traffic sign can be called a symbol by opposition to an arbitrary sign where there is no connection between the sign and its meaning. This distinction and the correlated terminology appear at the beginning of the Cours de linguistique générale by Saussure promoting the virtues of arbitrary signs. A typical arbitrary sign is the letter "a", often called "The first letter of the alphabet". This name, a definite description, does not reflect the very sign itself, nor its meaning which does not properly exist, but its position in a system of signs which is used to produce meaning. "a" has no proper name other than itself. 
This way to use the word "symbol", by contrast to "arbitrary sign", is not a Saussurian idiosyncrasy like "signifier" and "significant", it is rather traditional, connected to the etymology of the word. There is another meaning of "symbol" that Saussure does not clearly distinguish. Saussure gave as an example of symbol the sign used to represent justice:

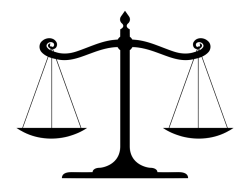

Both the "No right turn" traffic sign and this balance are symbols, in the sense that in both cases there is a connection between the sign and its meaning. But there is a further "symbolic" dimension with the balance. The above sign is a pictogram, i.e. a stylized picture of a balance. For this reason there is a connection between the sign and its meaning. Sometimes such kind of sign is also called an "icon". But this sign is not used just to represent a balance; it is used to represent justice through a balance. Such a representation is not iconic, it is prototypical: the idea of justice is represented through a particular example "symbolizing" it. The two aspects of the symbolic phenomenon are independent from each other: a traffic sign like the "No right turn" is not symbolically prototypical and we may have a prototypical symbolization not represented by a specific iconic sign, but it tends to be so due to the very spirit of the prototype: thinking the general through a particular and precise case. ${ }^{2}$

What about the sign " "? Is it a symbol or an arbitrary sign? Since it is a figure, a geometrical figure, one may think that it is rather a symbol than an arbitrary sign. It moreover shares with the pictogram phenomenon the fact that only one sign is used to express meaning by contrast to a combination of signs like in the case of an alphabetical word: "possibility". But what is the connection between the sign " " and the notion of possibility? Is there any?

What we have is a similarity between the form of the sign " " and the stone called diamond:

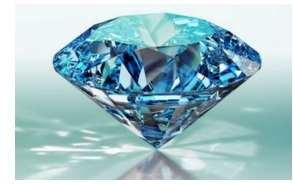

The sign " " can be considered as an icon of a diamond, this justifies its name. But can we say that the diamond stone is a prototypical example of the notion of possibility, in the same way that the balance is a prototypical example of the notion of justice? It is not obvious at first sight. Let us have a closer look.

The form of the sign " ", also called lozenge, is traditionally considered as sym- 
bolizing feminity and fertility, especially in this position. In the US Army it appears in the women airforce service pilots badge:

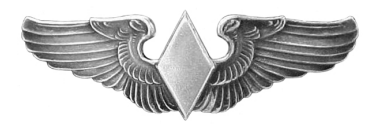

The fact that it symbolizes possibility can make sense if we consider that birth is the door open to new possibilities.

We also find the lozenge in the flag of Brazil, but in a laid position:

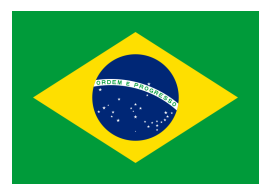

Considering that the lozenge symbolizes possibility, the Brazilian flag can be seen as pointing that Brazil is the country of possibilities, in the spirit of the origin of the flag $^{3}$ and of the nickname given to Brazil by Stefan Zweig: The Land of the Future. ${ }^{4}$

\section{The Mismatch of Possibility}

The sacred names of the modal operators and , respectively "possibility" and "necessity", do not properly match Yanet's vulgar way of speaking: on the one hand "necessary" does not appear in the black cloud; on the other hand possibility appears in the white cloud (cf. the third line) but this does not correspond to the meaning of the modal operator in modal logic.

We are in this paper mainly concerned with the second hand but let us say a few words about the first. Even when there are lots of black clouds in the sky, Yanet never says "It will necessarily rain tomorrow". Why? There are two possible different opposed explanations. ( ) She prefers to say "It will surely rain tomorrow in Acapulco" in a way synonymous to "It will most probably rain tomorrow in Acapulco" considering that meteorological previsions are only previsions or/and that the physical world is not predetermined. ( ) If Yanet believes that meteorological previsions are quite good and that the physical world is predetermined, she simply will say "It will rain tomorrow in Acapulco" without introducing "necessity". For the chica necessity would be redundant, pedantic or too much metaphysical.

Let us compare Yanet to a symptomatic modal guy like S5. For S5 there is the black cloud of necessity but not the grey cloud of probability. So if S5 was engaged for the weather forecast, he would never say "It will probably rain tomorrow in Acapulco". S5 would either say "It will rain" or "It will necessarily rain". When S5 says "It will

Principia 20(1): 99-115 (2016). 
necessarily rain" this implies that "it will rain" but not the converse. This is strange enough but we will discuss this question only during our next visit to Acapulco.

Let's come back to the white cloud. In modal logic, though the operator is called "possibility", it does not correspond to the white cloud because in all systems of modal logic we have as an axiom or/and as a tautology. According to this formula, if something is necessary it is possible. If it will necessarily rain, then it is possible than it will rain. Necessity is part of possibility, but not the converse, since is not a valid formula. We have therefore the following diagram:

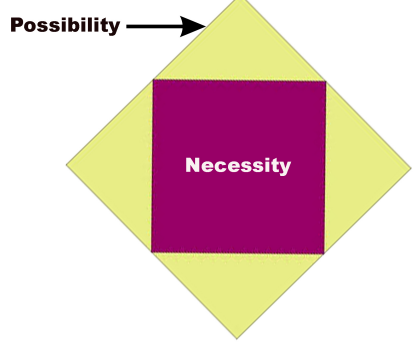

According to this configuration, "It is possible that it will rain tomorrow" may exclude the possibility of a dry situation. This is the magenta zone. If we don't want to exclude dry weather we have to stay in the yellow zone, the zone of non-necessary possibility. Is the yellow zone not the zone corresponding to the white cloud? Corresponding to what Yanet wants to express when she says "It might rain tomorrow"? This is a natural understanding of possibility in natural language. So why have modal logicians decided to use the word "possibility" in a different way?

In mathematics it is current to take a word from natural language as a source of inspiration and to use it with a meaning very roughly analogical - like "family", if not seriously deformed- like "root". This is not harmful because the objective is not to develop a mathematical concept that will clarify or explain the meaning of the word taken from natural language. Modal logic is part of mathematics, so maybe modal logicians proceed in a similar way? It seems it is not the case with "possibility".

Modal logicians have also the pretention to be philosophers ... They want to characterize what possibility is. In modal logic the intended meaning of the operator is supposed to be the notion of possibility. And what is the notion of possibility? Is it not the one showing up through a sentence like "It might rain tomorrow" or more explicitly in the synonymous sentence "It is possible that it will rain tomorrow".

One may want to make the distinction between the vulgar notion of possibility as it manifests through natural language and a more profound metaphysical idea, hidden behind. It is common in philosophy to use the same word, because often the philosopher wants to extract something essential from the vulgar notion and turn the 
notion more precise, or more general or more fundamental. This is what Plato did with "I ", Hegel with "Aufhebung", Heidegger with "Dasein".

Philosophers also use words from natural language, not so commonly used in daily life; marginal or forgotten words to which they give a kiss of life instead of creating a new word. This is what Frege did with "Truth-value" (Wahrheitswert) ${ }^{5}$ and what Wittgenstein did with "Tautology" (Tautologie). In philosophy creating new words is often suspicious because it looks like one creates a reality from the words, a wordy reality or a pseudo-scientific theory like with "Dianetics". In science it can make sense to create a new word, when a clearly defined new notion is introduced or/and when something new is discivered. In physics for example the word "quanton" has been introduced by Mario Bunge (1967), since the objects under scrutiny have properties which are in conflict with the idea of particle.

What is the situation with the modal operator ? Should we not introduce a new word? And why modal logicians don't deal with the yellow zone, the territory closely corresponding to the usual notion of possibility? Generally modal logicians don't play with an operator corresponding to the yellow zone, they introduce neither a sign, nor a name for it, it is for them a kind of blind spot. One of the reasons is because they think the operator is properly corresponding to the usual notion of possibility, indeed calling it "possibility".

\section{Columbus Confusion and the Square Compass}

Maybe we have here something that can be called a columbus confusion ${ }^{6}$ in the name of the famous explorer Christopher Columbus (1451-1506) arriving in America thinking it was India, calling the inhabitants "Indians" - a word which is still in used from Alaska to Patagonia, from Antigonish to Antofagasta. Sometimes it is slightly corrected as "Amerindians", a rather absurd adjustment.

Columbus confusion can be explained by the fact that since he believed the earth was round, going West he though he will reach India known from the East. He had a good compass and really went West but he didn't expect that there will be something in the middle. Can we explain the possibility phenomenon in a similar way?

Let us consider the famous square of opposition:

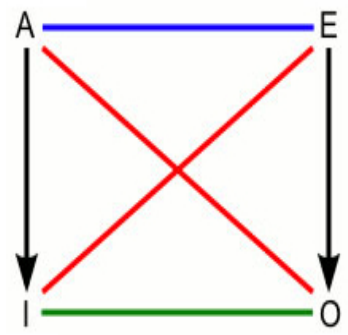

Principia 20(1): 99-115 (2016). 
In this square there are three notions of opposition: contrary in blue, contradictory in red, subcontrary in green and the notion of subalternation, which is a strict implication, i.e. A implies I and E implies O but not vice versa. "A", "E", "I", "O", the traditional names for labeling the four corners, correspond to propositions or concepts (embodied in propositions). At the beginning of the forecast we already became familiar with contrariety and contradiction. Let us furthermore define subcontrariety: two propositions are subcontraries iff they can be true together but not false together.

Now that we have understood how the square works, let us see how we can use it as a compass for exploring the land of modalities. Generally the A and E corners are respectively interpreted as necessity and impossibility. This makes sense: "It is necessary that it will rain" and "It is impossible that it will rain" cannot be true together.

Using this compass, should not possibility be located in the I corner, as the contradictory of impossible? Considering that the $\mathrm{O}$ corner is the contradictory of necessity, the bottom green line tells us then that "It will possibly rain" and "It will not necessarily rain" can be true together, that sounds good, Yanet should be happy. So considering that " " represents possibility and " " necessity, we have the following square:

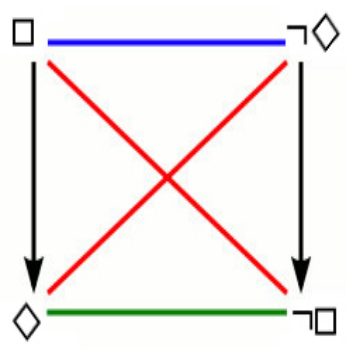

Is this not the right map? Not really: according to this we have exactly the property we were talking about: is a valid formula but not ; this is the meaning of the left arrow of subalternation. We are back to our problem: The possibility of rain in Acapulco does not necessary leave space for dry weather.

Like Columbus we wanted to reach something, the land of possibility, but we reached something else. Having Learned the lesson from the past, we should therefore change the name of the I-corner. Following a similar trail to what happened with Columbus's discovery, we can call the notion at this corner ameropossibility, until we have a bitter name.

After recognizing the truth, the fact that America was not India, Columbus was not completely lost. He knew that using the same compass, going further West he would reach India from the West "Indies" through the Panama canal. Can we do the same, reach the land of true possibility, non-necessary possibility, using our square compass? 
Maybe possibility is in another corner of the square. If we leave necessity and impossibility as they are, we have only one other choice, it is to put possibility in the $\mathrm{O}$-corner, but then what is impossible is possible, which is quite absurd.

Another option is to put possibility in the place of necessity or impossibility. If we put it in the place of necessity, possibility and impossibility are contrary that's fine, but then where to place necessity? If we put it in the I-corner, then what is possible is necessary, quite absurd, and we put it in the O-corner, then what is impossible is necessary, absurd again.

We can maintain possibility in the A-corner but not only change the place of necessity, but also the place of impossibility. Putting impossibility in the I-corner, we have that what is possible is impossible, absurd again. Putting impossibility in the $\mathrm{O}$-corner, we have either that what is necessary is impossible, if necessity is in the E-corner, or that that what is possible is necessary, if necessity is in the I-corner.

We have run through all the possibilities. Starting with possibility in another corner will give no better result due to symmetry. So we are not succeeding to catch non-necessary possibility with the square compass. We are in a situation much worse than Columbus. We have reached something which is not what we wanted to reach, ameropossibility, but we have no way to go further West. The square compass is taking us nowhere, just driving us crazy ... So we have to throw it to the sea compass, looking for another better compass, a sacrifice that hopefully Iemanjá will enjoy.

\section{The Triangle as a New Compass to Reach the Land of Possibility}

Maybe the land of modalities does not have four cardinal points, maybe more, maybe less. Occam's razor being a nice tool, let's try with less. Two would be a bit extreme, we don't necessarily want to get rid of necessity or impossibility, so we have a trichotomy to which we can give the following configuration:

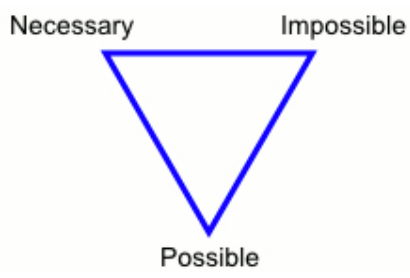

This is a triangle of contrariety. Any two notions are incompatible together but these pairs do not exclude a third case. "It is necessary that it will rain" and "It is possible that it will rain" cannot be true together, this is what we wanted, and they can be false together: when it is impossible that it will rain. Yanet would fully agree with such a trichotomy but the chica would use a simpler language: 
( ) It will rain tomorrow in Acapulco

( ) It might rain tomorrow in Acapulco

( ) It will not rain tomorrow in Acapulco

To this simpler way of speaking corresponds also a simpler way of conceiving reality.

Modern logic has promoted a strange ontology, mainly due to the young Wittgenstein, that still prevails, although the logico-philosophicus himself rejected it when reaching maturity. Like Yanet, Ludwig was not found of using modalities within propositions, he was even stricter than her, rejecting not only it will necessarily rain and it might rain or it will possibly rain. Nevertheless for him there were three situations for a proposition (Satz): to be always true, to be always false, to be couci-couça - sometimes true, sometimes false. He qualifies the first ones as Tautologies, (4.46). the second ones as Contradictions (4.46) and the third ones simply as Propositions (4.646): "A tautology's truth is certain (gewiss), a proposition's possible, a contradiction's impossible". For him only the third kind of propositions are "real" propositions, because only those are saying something about the world. Wittgenstein does not use "necessary" but "certain". And for Ludwig "certain" has not the same meaning as for Yanet. For him rain in Acapulco or in Vienna is something than cannot be certain. What is certain is It will rain or it will rain tomorrow in Acapulco. The only certainty is tautological, the phenomenon of rain is merely possible like all other facts, all atomic propositions are only possible.

Notwithstanding Wittgenstein is using the word "possibility" in harmony with the above triangle, not confusing possibility with ameropossibiliy. Ontologically speaking the word "contingency" has also been used and Wittgenstein has a position which is radically opposed to the one of Spinoza who declared in his Ethics: "Nothing in the universe is contingent, but all things are conditioned to exist and operate in a particular manner by the necessity of the divine nature (In rerum natura nullum datur contingens sed omnia ex necessitate divinæ naturæ determinata sunt ad certo modo existendum et operandum)." (PROP. XXIX). For Wittgenstein only tautologies are divine...

Anyway the triangle is a good compass, leading us to the land of possibility. The triangle compass has been promoted by Nikolai Vasiliev ${ }^{7}$ to replace the square, not to navigate in the ocean of modalities, but in the ocean of quantifiers. The square was in fact developed for this ocean, where it also leads to some confusions, when placing some in the I-corner, all in the A-corner, none in the E-corner (the standard square interpretation of the quantifiers). ${ }^{8}$ The alternative solution is the following triangle: 


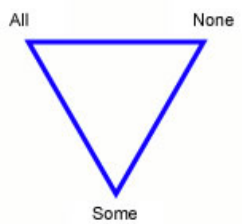

Jean-Yves Béziau

Variations of this quantificational triangle of contrariety are the following triangles for space and time:
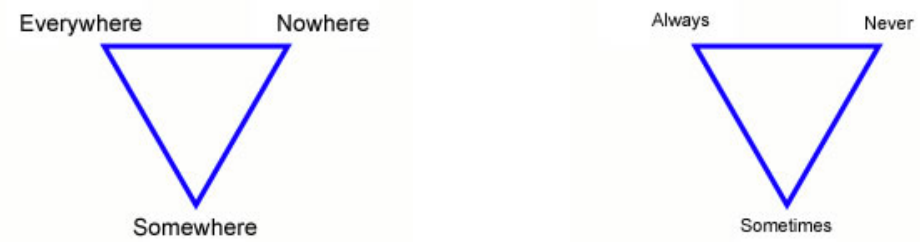

And such a compass can also be used when you drive your car or you pen:
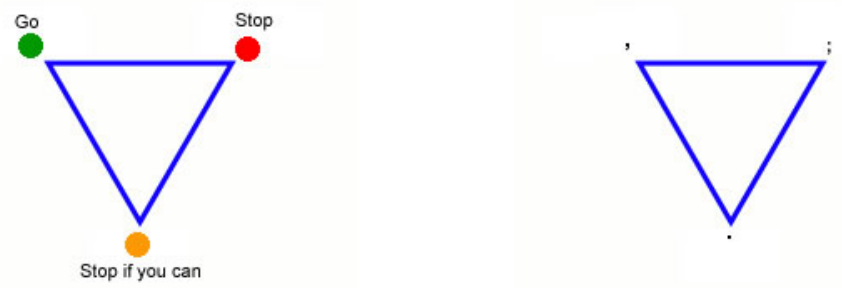

\section{From the Triangle to the Hexagon of Opposition}

Robert Blanché (see his seminal 1966 book) had the idea that the triangle of contrariety is a fundamental compass for our thought, but he pointed out that we can find back the square from this triangle of contrariety by contradictorily linking it with a dual triangle of subcontrariety giving birth to a hexagon in which the square is enclosed. As a result we have the following structure:

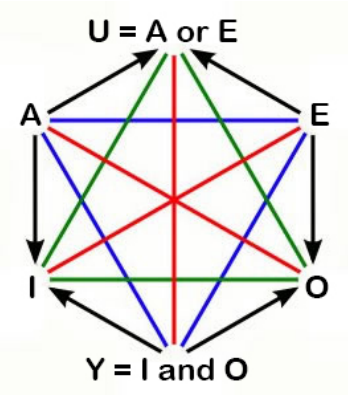

Principia 20(1): 99-115 (2016). 
If the AEY triangle is interpreted as the Necessity-Impossibility-Possibility triangle that we have previously presented the Y-vertex perfectly defines non-necessary possibility: $Y$ is what is not impossible and not necessary. This is the posture of Yanet when she says "It might rain tomorrow in Acapulco". We cannot say that Blanché chose the letter "Y" for this vertex in her honor, because the chica was not yet born. Anyway this is a nice coincidence.

But something not so nice is the decision to call the Y-vertex "contingency", and to keep the name "possibility" for the I-vertex:

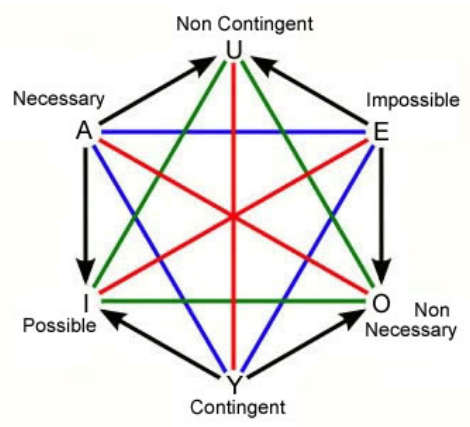

We don't know exactly why this choice was made. Calling the Y-vertex "contingent" seems fine if we think of Spinoza. But the way the word "possible" is used in natural language also corresponds to this position. The problem is that it is not easy to find a name for the I-vertex, ameropossibility is a bitter name.

In the case of the deontic hexagon we have a better situation, because to the I-vertex and the Y-vertex reasonably correspond in natural language two names: "allowed" and "optional":

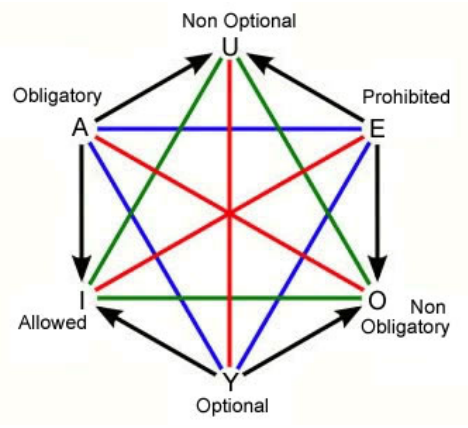

However in this hexagon the O-vertex does not have a proper name, it is just artificially called "non-obligatory". The naming problem of the O-vertex also exists in the hexagon of quantifiers and the hexagon of alethic modalities. 


\section{From Contingency to Possibility}

One may want to call the O-vertex in the alethic hexagon of modalities "contingency" because it is opposed to necessity. The opposition necessity-contingency is a traditional opposition which has different faces. This can be illustrated by the following table:

\begin{tabular}{|c|c|}
\hline $\mathbf{1}$ & $\mathbf{0}$ \\
\hline Necessity & Contingency \\
\hline Determinism & Indeterminism \\
\hline Causality & Chance \\
\hline
\end{tabular}

By contrast with the table presented at the beginning of the forecast, this is a table of dichotomies, i.e. contradictory opposites. However this line of thought is incompatible with the square of modalities where the red diagonal necessarycontingent crosses the diagonal possible-impossible, because then what is impossible is contingent - this is the meaning of the right subalternation arrow of the square, even much more absurd than the left subalternation arrow. The two pairs necessity; contingency and possibility; impossibility can be considered as two pairs of contradictories separately but they don't fit well together.

If we consider the pair necessity; contingency in an existentialist perspective, impossibility has no place, because the world cannot be impossible, it is! That's why in this context it may seem better not to use the word "possible", "contingent" is better, leaving no place for impossibility.

On the other hand if we consider the pair possibility; impossibility, it makes sense to introduce necessity as a third term. Let us have a look at the following pictogram:

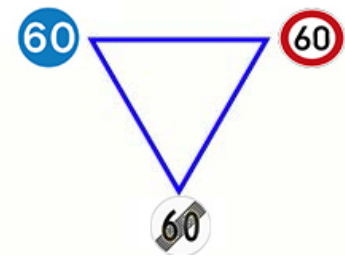

This can be seen as a deontic contrary triangle: obligatory, prohibited and optional. But deontic modalities can be seen as particular cases of alethic modalities. In other words, the deontic modalities can be interpreted in an alethic way: according to traffic laws it is necessary to drive at a speed higher than $60 \mathrm{~km} / \mathrm{h}$ (blue sign), or it is impossible to drive at a speed higher than $60 \mathrm{~km} / \mathrm{h}$ (blue sign), or it is possible to 
drive at a speed higher than $60 \mathrm{~km} / \mathrm{h}$ (grey sign). Here the word "contingent" would not fit very well.

In any case, in the square of modalities, it does not make sense to give the label "contingent" to the O-corner and it is pernicious to give the label "possible" to the I-corner. In the hexagon of modalities we can call the Y-vertex either possible or contingent. But "possible" sounds better for two reasons: (1) as we have seen "contingent" is good for a dichotomy necessity-contingency with no impossibility involved; if we give the label "contingent" to the Y-vertex (2) one may think we are talking about this kind of contingency, (3) one may think that the Y-vertex is not the usual notion of possibility (especially if the I-vertex is labeled as "possibility").

If we consider the two operators and, and if write instead of and instead of we have the following two configurations corresponding respectively to the left and right subalternation arrows of the square:
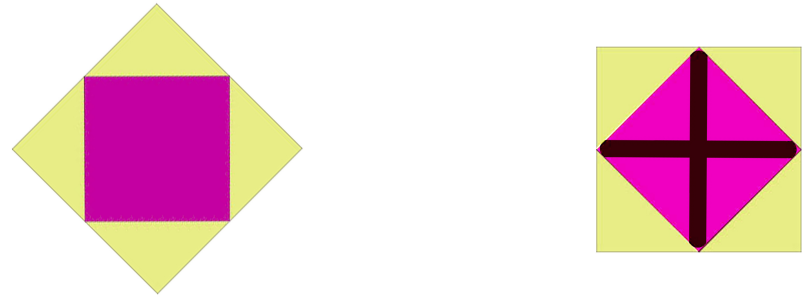

In both cases non-necessary possibility is in yellow and corresponds to the (union of) 4 yellow triangles. According to the left picture it is diamond minus box, according to the second configuration is it crossed-box minus crossed-diamond. This yellow zone corresponds to the Y-vertex of the hexagon.

The sign " " has been introduced by Montgomery and Routley (1966) to denote the operator corresponding to it and they have introduced the reverse sign " " to denote the operator corresponding to the U-vertex they have called "non-contingent". 9

Following the structure of the hexagon we have:

$$
\begin{aligned}
& = \\
& =
\end{aligned}
$$

The hexagon is a general compass for the land of modalities, valid for most of the modal systems of logic. ${ }^{10}$ If we use Kripke semantics we can directly define the truth of a formula in a very simple way, without going through and .

is true in a world $w$ iff

there is an accessible world $w_{1}$ in which is true and an accessible world $w_{2}$ in which is false 
This is indeed the definition given by Montgomery and Routley. As it is known in a modal logic like S5 it is possible to define all the other five modalities from the operator using negation, conjunction and disjunction. But it is also possible to do the same starting with the operator . And why not starting with if possibility is our main concern? ${ }^{11}$ Or without being too reductionist we can start with a contrariety triangle of modalities which is has the heart of the hexagon.

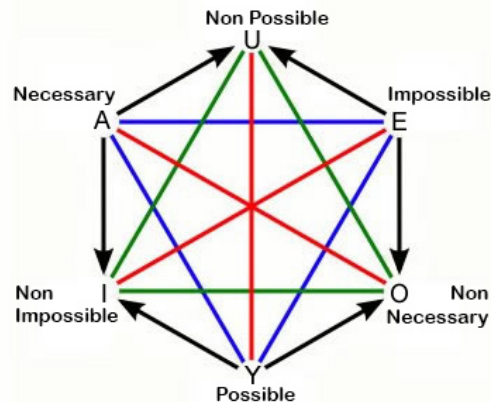

According to the structure of this hexagon, we have the following table:

\begin{tabular}{|c|l|l|}
\hline U & Non-Possible & Necessary or Impossible \\
\hline I & Non-Impossible & Possible or Necessary \\
\hline O & Non-Necessary & Possible or Impossible \\
\hline
\end{tabular}

One may think it is silly that the "U", "I", "O" vertices don't have proper names, but we are not guilty for that. The sin is to call the I-vertex possibility.

\section{References}

Bazhanov, V. 2016. Nicolai Vasiliev. Internet Encylopedia of Philosophy.

Becker Arenhart, J. R. 2015. Liberating paraconsistency from contradiction. Logica Universalis 9: 523-44.

Béziau, J.-Y. 2002. S5 is a paraconsistent logic and so is first-order logic. Logical Investigations 9: 301-9.

- 2002. Are paraconsistent negations negations?. In W. Carnielli et al. (eds), Paraconsistency: the logical way to the inconsistent. New York: Marcel Dekker, p.465-86..

- 2003. New light on the square o opposition and its nameless corner. Logical Investigations 10: 218-32.

- 2005. Paraconsistent logic from a modal viewpoint. Journal of Applied Logic 3: 7-14. . 2006. The Paraconsistent logic Z - a possible solution to Jaskowski's problem! Logic and Logical Philosophy 15: 99-111.

- 2010. What is a possible world? In G. Imaguire and D. Jacquette (eds.) Possible worlds: logic, semantics and ontology. Munich: Philosophia Verlag, p.25-37.

Principia 20(1): 99-115 (2016). 
2012. History of the concept of truth-value. D. M. Gabbay, J. Pelletier and J. Woods (eds.) Handbook of the history of logic, Vol. 11 - Logic: a history of its central concepts. Amsterdam: Elsevier, p.233-305.

- 2012. The new rising of the square of opposition. In J.-Y. Beziau and D. Jacquette (eds.) Around and beyond the square of opposition. Basel: Birkhäuser, p.6-24.

- 2012. The power of the hexagon. Logica Universalis 6: 1-43.

- 2013. The metalogical hexagon of opposition. Argumentos 10: 111-22.

- 2014. La puissance du symbole. In J.-Y.Beziau (ed.) La pointure du symbole. Paris: Petra, p.9-34.

- 2016. Disentangling contradiction from contrariety via incompatibility. Logica Universalis 10: 157-70.

—. 2016. Le possible et l'impossible: au-delà de la dichotomie. In J. Ferrari and and A. Lajohmri (eds.) Actes du 35ème congrès de l'ASPLF. Paris: Vrin, p.33-64.

- 2016. Is modern logic non-Aristotelian? In D. Zaitsev (ed.) Nikolai Vasiliev's Logical Legacy and Modern Logic. Dordrecht: Springer.

Béziau, J.-Y.; Basti, G. (eds.) 2016. The square of opposition - a cornerstone of thought. Basel: Birkhäuser

Béziau, J.-Y., Gerogiorgakis, S. (eds.) 2016. New dimensions of the square of opposition. Munich: Philosophia.

Béziau, J.-Y.; Giovagnoli, R. (eds.) 2016. Special Issue of Logica Universalis, issue 2-3, volume 10.

Béziau, J.-Y.; Jacquette, D. (eds.) 2012. Around and beyond the square of opposition. Basel: Birkhäuser.

Béziau, J.-Y.; Payette, G. (eds.) 2008. Special Issue of Logica Universalis, issue 1, volume 2.

- (eds.) 2012. The square of opposition: a general framework for cognition. Bern: Peter Lang.

Béziau, J.-Y.; Read, S. (eds.) 2014. Special Issue of History and philosophy of logic, issue 4, volume 35.

Blanché, R. 1966. Structures intellectuelles: Essai sur l'organisation systématique des concepts. Paris: Vrin.

Bunge, M. 2007. Foundations of physics. New York: Springer.

Gabriel, G. 1984. Fregean connection: Bedeutung, Value and Truth-Value. The Philosophical Quarterly 34: 372-6.

Humberstone, L. 1995. Conventionalist and contingency-oriented modal logics. Notre Dame Journal of Formal Logic 36: 214-29.

Kripke, S. 1959. A completeness theorem in modal logic. Journal of Symbolic Logic 24: 1-14.

Kuhn, S. T. 1995. Minimal non-contingency logic. Notre Dame Journal of Formal Logic 36: 230-34.

Lachance, G. 2016. Platonic Contrariety (enantia): Ancestor of the Aristotelian Notion of Contradiction (antiphasis)? Logica Universalis 10: 143-56.

Łukasiewicz, J. 1920. O logice trojwartosciowej. Ruch Filozoficny 5: 170-1.

- 1952. A system of modal logic. Journal of Computing System 1: 111-49.

Montgomery, H. and R. Routley. 1966. Contingency and non-contingency bases for normal modal logics. Logique et Analyse 9: 318-28.

- 1968. Non-contingency axioms for S4 and S5. Logique et Analyse 11: 58-60.

Principia 20(1): 99-115 (2016). 
Pizzi, C. 2016. Generalizations and composition of modal squares of opposition. Logica Universalis 10: 313-25.

Routley, R. 1971. Conventionalist and contingency-oriented modal logics. Notre Dame Journal of Formal Logic 12: 131-52.

Wittgenstein, L. 1921. Tractatus Logico-Philosophicus. Annalen der Naturphilosophie 14: 185362.

JEAN-YvEs BÉZIAU

Brazilian Council for Scientific and Technological Development Brazilian Academy of Philosophy and International Academy for Philosophy of Sciences

Departmento de Filosofia Universidade Federal do Rio de Janeiro Largo de São Francisco de Paula, 1 20051-070 Rio de Janeiro, RJ

BRAZIL

jyb@ufrj.br

\section{Notes}

${ }^{1}$ About the confusion between contrariety and contradiction see our recent papers"Round square are no contradictions" (Béziau 2015), "Disentangling contradiction from contrariety via incompatibility" (Béziau 2016) and the 2015 paper by J. R. Becker Arenhart"Liberating paraconistency from contradiction"; and see (Lachance 2016) for the development of these notions in ancient Greece. Concerning recent works about the square of opposition, see (Béziau/Payette 2008/2012), (Béziau/Jacquette 2012), (Béziau/Read 2014), (Béziau/GanKrzywoszynska 2016), (Béziau/Basti 2016), (Béziau/Giovagnoli 2016).

${ }^{2}$ About the the notion of symbol see our introductory paper "La puissance du symbole" in the book La pointure du symbole (2014) we have edited, a collection of papers related to a congress we organized at the University of Neuchâtel in 2005 challenging the notion of arbitrary sign promoted by Saussure.

${ }^{3}$ This is the official flag of Brazil since November 19, 1989 (three stars corresponding to three new states were added in 1992), after the proclamation of the Republic on November 15. During four days was used a flag with the same shape as the flag of the United States. This choice was reverted in favor of a shape similar to the previous flag of the Empire of Brazil (1822-1989), with a gold lozenge on a green rectangle, designed by Jean-Baptiste Debret, who was a follower of Napoleon Bonaparte, to whom the dictum "Impossible n'est pas français" is attributed.

${ }^{4}$ This is a really interesting book. Zweig is one of the best writers of the first half of the XXth century. He committed suicide in Petrópolis on February 22, 1942. The same day he wrote a short note entitled "Declaração", which was made available to the public 70 years later by the National Library of Israel. In this note he wrote about Brazil: "Every day I learned to love this country more, and I would not have asked to rebuild my life in any other place after the world of my own language sank and was lost to me and my spiritual homeland, Europe, destroyed

Principia 20(1): 99-115 (2016). 
itself." The house where he was living in Petrópolis with his wife has been transformed into the museum Casa Stefan Zweig.

${ }^{5}$ About Wahrheitswert see Gabriel 1984 and our 2012 paper "A history of truth-values".

${ }^{6}$ We introduced the notion of columbus confusion in our 2002 paper "Are paraconsistent negations negations?"

${ }^{7}$ About Vasiliev, see Bazhanov 2016 and our 2016 paper "Is modern logic non-Aristotelian?".

8 About the square of quantification, see our 2012 paper "The power of the hexagon".

${ }^{9}$ Apparently there were no relations between Blanché and Montgomery-Routley. The logic of contingency (and non-contingency) was further developed in Australia by Humberstone and Kuhn.

${ }^{10}$ Eukasiewicz (1953) uses the square as a basic framework for the development of systems of modal logic. (Pizzi 2016) shows however that the square does not necessarily apply to any modal system whatsoever.

11 The logic Z (Béziau 2002, 2006) was developed starting with the O-corner, our main concern was there a paraconsistent negation.

Principia 20(1): 99-115 (2016). 